\title{
New roles for the nucleolus in health and disease
}

Lorena Núñez Villacís ${ }^{1}$, Mei S. Wong ${ }^{1,2,3}$, Laura L. Ferguson ${ }^{1}$, Nadine Hein ${ }^{1}$, *Amee J. George ${ }^{1,4,5}$ and *Katherine M Hannan ${ }^{1,6}$.

${ }^{1}$ ACRF Department of Cancer Biology and Therapeutics, John Curtin School of Medical Research, The Australian National University, Acton 2601, Australia; ${ }^{2}$ Oncogenic Signalling and Growth Control Program, Peter MacCallum Cancer Centre, Melbourne 3000, Australia; ${ }^{3}$ Sir Peter MacCallum Department of Oncology, The University of Melbourne, Parkville 3010, Australia; ${ }^{4}$ School of Biomedical Sciences, University of Queensland, St Lucia 4067, Australia; ${ }^{5}$ Department of Pathology, The University of Melbourne, Parkville 3010, Australia; ${ }^{6}$ Department of Biochemistry, The University of Melbourne, Parkville 3010, Australia

Subtitle: New roles for the nucleolus in health and disease

\section{Corresponding author:}

Lorena Núñez Villacís

E-mail: lorena.nunez@anu.edu.au

Key words: Nucleolus, ribosome biogenesis, nucleolar surveillance, cancer, ribosomopathies, neurological disorders

This is the author manuscript accepted for publication and has undergone full peer review but has not been through the copyediting, typesetting, pagination and proofreading process, which may lead to differences between this version and the Version of Record. Please cite this article as doi: 10.1002/bies.201700233 


\begin{abstract}
Over the last decade, our appreciation of the importance of the nucleolus for cellular function has progressed from the ordinary to the extraordinary. We no longer think of the nucleolus as simply the site of ribosome production, or a dynamic subnuclear body noted by pathologists for its changes in size and shape with malignancy. Instead, the nucleolus has emerged as a key controller of many cellular processes that are fundamental to normal cell homeostasis and the target for dysregulation in many human diseases; in some cases, independent of its functions in ribosome biogenesis. These extra-nucleolar or new functions, which we term 'non-canonical' to distinguish them from the more traditional role of the nucleolus in ribosome synthesis, are the focus of this review. In particular, we explore how these non-canonical functions may provide novel insights into human disease and in some cases new targets for therapeutic development.
\end{abstract}

\title{
1. The nucleolus.
}

The nucleolus is a dynamic, non-membrane bound compartment within the nucleus, and is the hub for ribosomal RNA (rRNA) synthesis and assembly with ribosomal proteins (rproteins) to generate the ribosome subunits ${ }^{1-6}$. The nucleolus is surrounded by the peri-nucleolar heterochromatin $(\mathrm{PH})$ and consists of three distinct structural regions defined by their appearance and the presence of specific components required for ribosome synthesis: i) the fibrillar center (FC); ii) dense fibrillar component (DFC); and iii) granular component (GC) (Figure 1) $)^{4,5,7}$.

Nucleoli form around actively transcribed clusters of the 200-400 rRNA genes, which are typically arranged as tandem-repeats ${ }^{5}$, and as a consequence occupy the same three dimensional nuclear space. In non-transformed human cells these genes localize to the short arms of five acrocentric chromosomes $(13,14,15,21,22)$, forming the nucleolar organizer regions (NORs). Nucleoli assemble in the early G1 phase of the cell cycle, first as a number of smaller units, which later coalesce into 1-2 larger functional nucleoli containing multiple NORs. At this stage, the nucleoli are associated with PH derived from DNA close to the NORs. The rate of ribosomal gene (rDNA) transcription does not peak until S phase, and remains elevated in G2 until the nucleoli disassemble at the end of mitosis. Interestingly, a number of nucleolar 
proteins remain associated with the rDNA throughout mitosis, eg., upstream binding transcription factor (UBTF, also called UBF). Disassembly in M phase is triggered, at least in part, by cyclin dependent kinases (CDK), specifically CDK1-cyclin B phosphorylation of RNA Polymerase (Pol) I components which shuts down rDNA transcription ${ }^{2,3,6}$. The size and number of nucleoli per cell can vary considerably, for example during differentiation or malignancy. However, broadly speaking, the "larger the nucleoli, the faster the cell divides," which correlates with higher rates of ribosome biogenesis and growth.

\subsection{The nucleolus and ribosome biogenesis}

The majority of ribosome biogenesis occurs in the nucleolus ${ }^{2}$ and requires all three RNA polymerases; Pol I and Pol III generate the rRNA's (28S, 18S, 5.8S, 5S), and Pol II the various rproteins and obligatory processing/modulatory factors (Figure 2). To achieve the required coordination, every step is tightly regulated via signaling pathways that respond to growth/proliferation, differentiation and stress cues ${ }^{2,8-10}$. Transcription of rDNA by Pol I generates a 47S rRNA precursor commencing with the regulated formation of a pre-initiation complex (PIC) at the promoter and recruitment of RRN3, toposiomerase II $\alpha$ and the Pol I complex ${ }^{11,12}$. PIC formation is regulated at multiple levels, including competitive binding by other proteins, posttranslational and/or epigenetic modifications $s^{3,6,13}$. While the rate of transcription is dynamically regulated ${ }^{14-16}$, it remains controversial as to which step is rate-limiting, traditionally this was considered to be initiation, however recent evidence supports elongation and/or processing of the rRNA precursor ${ }^{14-16}$. In reality, it is likely that all steps require modulation in unison to achieve the dynamic range of rRNA synthesis observed in growing cells. Consistent with this, master regulators have evolved such as the oncoprotein and transcription factor MYC which can directly and indirectly regulate all three Pol's (Figure 2), thus ensuring coordination of all components required for ribosome biogenesis ${ }^{9,10}$.

The rRNA also requires extensive processing, which is only beginning to be understood in eukaryotes ${ }^{17-19}$, followed by a series of conformational changes to allow rproteins to cooperatively bind. Factors, such as snoRNPs and assembly complexes, facilitate the assembly and maturation of the pre-40S and pre-60S subunits, before 
export to the cytoplasm for the final maturation steps to a functional ribosome ${ }^{18,20-22}$. Intriguingly, domains that are essential for ribosome function, such as the peptidyltransferase domain, tend to form during the latter stages of assembly, perhaps as a means to prevent any translation from immature ribosomes ${ }^{1,22,23}$.

\subsection{Insight from the nucleolar proteome}

In 2002, seminal nucleolar proteomic studies were published by Andersen ${ }^{24}$ and $\operatorname{Scherl}^{25}$ and collaborators, which provided strong, but somewhat unexpected evidence that the nucleolus was not just the site of ribosome biogenesis, but also a reservoir of 'non-ribosomal' proteins. Andersen identified 271 proteins, of which 11 relocated to the nucleolus when all three Pol's were inhibited by the transcription inhibitor Actinomycin $\mathrm{D}^{24}$, while the Scherl study ${ }^{25}$ identified 213 proteins. When combined, these studies identified a total of $\sim 350$ nucleolar proteins, although due to assay limitations, some of the 'expected' proteins were missing (e.g. RRN3). Recent studies using technically improved mass spectrometry have expanded this list to over 4500 proteins which resulted in the curation of a Nucleolar proteome database ${ }^{26}$ and the Human Protein Atlas (www.proteinatlas.org).

Perhaps even more surprising than the sheer number of nucleolar proteins identified, was the diversity of their functions. Indeed over $30 \%$ had seemingly no connection to ribosome biogenesis. Scherl ${ }^{25}$ and Andersen's ${ }^{24}$ initial work identified six major ontological categories (chromatin structure, mRNA metabolism, translation, chaperones, fibrous proteins, others) which has now been expanded to include control of cell cycle and proliferation, cell death, telomere metabolism, RNA posttranslational modification, energy production, and DNA replication, recombination or repair $^{26-28}$. The identification of these "non-ribosome biogenesis associated proteins" opens up a number of possibilities, perhaps they have a nucleolar function, localize there to be modified or are sequestered and released as a means of regulation. There is emerging literature supporting such possibilities. For example, the poly(A)-specific ribonuclease PARN and non-canonical poly(A) RNA polymerase PAPD5 localize to the nucleolus, while their accepted role is to process mRNAs in the nucleoplasm. However, recent studies demonstrated that nucleolar PARN and PAPD5 can mediate 
post-translational modification and maturation of small nucleolar RNAs (snoRNAs) which in turn modulate rRNA, tRNA and perhaps mRNA ${ }^{29,30}$.

The first reported, and now accepted, non-canonical role for the nucleolus is its ability to act as a "stress sensor"7,31,32. That is the nucleolus responds to a range of stresses by facilitating the accumulation of the tumor suppressor protein $\mathrm{p} 53$. This has been termed the 'nucleolar stress response' (NSR), but a more accurate description might be the 'nucleolar surveillance pathway' (NSP), since the pathway seems to function constitutively as a cellular rheostat to monitor ribosome production and fidelity, and to titrate p53 levels accordingly. With this change in thinking, it is possible to argue that NSP is an evolved canonical function of the nucleolus, linked to ribosome synthesis. However for this review we will discuss it as a non-canonical function of the nucleolus to distinguish it from the core functions of the nucleolus, the synthesise and assembly of the 40S and 60S ribosomal subunits.

\section{The non-canonical roles of the nucleolus}

\subsection{The nucleolus as a site of protein sequestration and release}

Studies have reported that proteins flux in and out of the nucleolus in response to various stressors (e.g. UV irradiation, hypoxia, serum starvation) or drug treatments (e.g. Etoposide, Actinomycin D) ${ }^{7,31-33}$. In general, these studies reported that acute stress mediates a net efflux of proteins, irrespective of their function, and proposed that protein sequestration in the nucleolus is largely constitutive (passive), whereas their release was dynamic (regulated). There are however some notable exceptions, including RelA (p65 subunit of $\mathrm{NF}-\mathrm{kB}^{34}$ ) and the promyelocytic leukemia tumour suppressor (PML) ${ }^{35}$, which are actively sequestered to the nucleolus during stress and mediate apoptosis. Another example is the heat shock protein 70 which enters the nucleolus in response to stress (including viral infection), perhaps to facilitate restoration of nucleolar function ${ }^{36}$. Other proteins such as nucleolin (NCL), and nucleophosmin (NPM1) are described as scaffolds, anchors or "nucleolar hubs" that facilitate nucleolar localization of proteins ${ }^{37}$. For example, NPM1 interacts and shuttles proteins between cellular compartments, but can also bind nucleic acids with a preference for G-quadruplex sequences, common to the rDNA. Thus NPM1 has a dual role in the nucleolus, as a protein chaperone and an anchor ${ }^{37}$. Other proteins, 
such as nucleostemin (NS) interact with numerous proteins, using a nucleolar localization sequence to target them to the nucleolus ${ }^{38}$. Interestingly, nucleolar protein localization can also be regulated by environmental changes, for example, altered cellular $\mathrm{pH}$ mediates stabilization of the von Hippel-Lindau protein, mediating nucleolar accumulation ${ }^{28}$.

Nucleolar protein sequestration and release provides a convenient mechanism to modulate cellular processes. For example, by retaining critical cell cycle proteins (e.g. cdc14, MDM2) in the nucleolus, the cell has a means of both temporally and spatially regulating the rate of cell division and coupling it to growth through the role of the nucleolus in ribosome synthesis and assembly ${ }^{39,40}$. Similarly nucleolar retention of DNA repair proteins (e.g. DDB1, PARP1, PNKP, XRCC1), would facilitate simultaneous release into the nucleoplasm, and thus a coordinated response to stress stimuli $^{7}$. The non-canonical apurinic/apyrimidinic endonuclease 1 (APE1), a major cellular scavenger of damaged DNA, was also identified in the nucleolar proteome. APE1 not only interacts with NPM1 and nucleolar $\mathrm{rDNA}^{41}$, but functions within the nucleolus to provide quality control of the highly transcribed rRNA, which is prone to error $^{28}$. Thus, APE1 may be a conduit between the DNA repair processes and RNA metabolism.

Proteins associated with other DNA repair mechanisms (e.g. homologous recombination (HR): RAD50 \& 51, WRN, XRCC5, DNA-PK; non-homologous end joining (NHEJ): PARP1, PNKP, XRCC1) also localise within the nucleolus?. Interestingly, the mechanism by which the rDNA is repaired is still controversial with publications implicating both $\mathrm{HR}^{42}$ and $\mathrm{NHEJ}^{43}$, though the data of McStay and colleagues on HR associated repair appears particularly compelling. Clearly, a significant body of work is required to understand the varied mechanisms and extent to which localisation/release of nucleolar proteins controls cellular homeostasis. What is clear however is that insults to the cell, that perturb the normal functions of the nucleolus, would have profound consequences for any sequestration/release processes. We speculate this is likely to contribute to the therapeutic effect of targeted Pol I inhibitors in the treatment of cancer (described below).

\subsection{The p53-dependent nucleolar surveillance pathway (p53NSP)}


The canonical p53NSP, describes a signalling pathway in which p53 is activated in response to a broad range of cellular stresses ${ }^{44}$. Specifically, these stresses perturb ribosome biogenesis and function, resulting in p53-dependent cell cycle arrest, and in extreme cases, apoptotic cell death. Intrinsic stresses that induce NSP include, mutations in rproteins or other components of the ribosome biogenesis pathway (eg: ribosomopathy diseases ${ }^{31,45}$ ), mutations in components of Pol II, DNA damage, extreme environmental conditions, hyperproliferative signals, oxidative stress, nutrient deprivation, hypoxia, osmotic stress, viral infections, energy deprivation, and oncogenic stress ${ }^{46}$. As described above, rather than being an acute response to stress, it is more likely that the p53NSP functions constitutively in proliferating cells as a balancing mechanism matching cellular proliferative capacity "fitness" with the rate of ribosome biogenesis.

Specifically the p53NSP mediates the accumulation of excess free rproteins, which are not required for ribosome synthesis. In particular the RPL5/L11/5S ribonucleolar protein (5SRNP) complex which is no longer being incorporated into the ribosome binds and sequesters the p53 E3 ubiquitin ligase MDM2, resulting in accumulation of $\mathrm{p} 53^{13,31}$. Alternatively during conditions of high demand for ribosome biogenesis, the 5SRNP is efficiently incorporated into newly assembled ribosomes and thus MDM2 is free to target p53 for degradation, thereby reducing p53 protein abundance (Figure 3). This model was perhaps best described by Rubbi and Milner ${ }^{44}$ who proposed that 'the nucleolus as a stress sensor is analogous to the 'dead man's foot' safety system: a p53 response will occur unless the nucleolus is constantly capable of promoting its degradation".

Interestingly, a number of other rproteins have been postulated to mediate the release of MDM2 from p53, however it is now more widely accepted that the 5SRNP complex is the predominant culprit ${ }^{47,48,49,50}$. Our unbiased functional RNAi screen supports this observation as depletion of RPL5 or RPL11, but none of the other tested rproteins, prevented p53 stabilization (unpublished observations). It is clear that other rproteins mediate effects on $\mathrm{p} 53$, but these are likely to be independent of the interaction with MDM2. For example, RPL26 binds the 5' untranslated region of p53 mRNA and promotes its translation ${ }^{51}$, where as RPS26 binds and directly influences 
p53 transcriptional activity ${ }^{52}$. The relative importance, of these mechanisms modulating p53 abundance and activity remains unclear.

\subsubsection{Other p53-dependent, but rprotein-independent, regulators of NSP}

Recent studies revealed that p53NSP is more convoluted than previously thought, with proteins not part of this complex identified as interactors with, and impacting on, MDM2 mediated degradation of p53 also in response to nucleolar stress. For example, Xie and colleagues ${ }^{53}$ demonstrated that stress caused translocation of the nucleolar protein cellular senescence-inhibited gene (CSIG) to the nucleoplasm, which bound MDM2 and inhibited its function, thus p53 accumulated. Intriguingly, CSIG is structurally similar to rproteins harbouring an N-terminal ribosomal L1 domain which mediates its binding to MDM $2^{53}$. Other nucleolar proteins, including ARF, NS and NPM1, also use a similar mechanism of modulating p53 abundance ${ }^{31,53,54}$. As an additional layer of complexity, when perturbed, nucleolar proteins such as the rRNA processing protein RRP15, which is required for pre-40S/SSU and pre-60S/LSU ribosomal subunit formation and rDNA transcription, can promote 5SRNP excess which then outcompetes p53 for its interaction with MDM2 $2^{55}$.

Interestingly CSIG and ARF also mediate a p53-independent $\mathrm{NSP}^{31}$. Specifically, CSIG in the absence of p53 activates the ATR-Chk1- $\gamma \mathrm{H} 2 \mathrm{AX}$ DNA replication/damage checkpoint, mediating a delay in S-G2 which culminates in cell death. ARF, rather than binding MDM2, interacts and antagonizes MYC and E2F, mediating cell cycle arrest. In fact, there is now a growing list of proteins that so far have only been associated with a p53-independent NSP which are discussed below.

\section{3 p53-independent mechanisms of sensing nucleolar stress}

Depletion of the largest subunit of Pol I in p53-silenced cells inhibits rDNA transcription and initiates the NSP, mediating a G1/S phase cell cycle arrest. This occurs via phosphorylation of retinoblastoma protein and reduced expression of E2F1-regulated genes, especially those critical for $S$ phase ${ }^{56}$. Intriguingly, even in the absence of p53, the binding of "free" RPL11 (i.e not incorporated in a ribosomal subunit) to MDM2 is still able to mediate cell cycle arrest but via proteosomal degradation of $\mathrm{E} 2 \mathrm{~F} 1^{56}$. Induction of the NSP by the nucleic acid synthesis inhibitor 5- 
Fluorouracil (5FU) leads to G1 cell cycle arrest and apoptosis, and this process was mediated by RPL3-directed elevation of p21 expression. Specifically ERK phosphorylation enhanced RPL3 and Sp1 binding to the p21 promoter increasing transcription at the expense of Sp1-dependent cystathione-beta-synthase (CBS) transcription and free RPL3 triggered translocation of CBS to the mitochondria inducing apoptosis 57 .

Not surprisingly, the characterisation of the nucleolar proteome has led to the identification of a collection of novel NSP mediators. Peter Pan (PPAN) is one such protein; while identified in the nucleolus, its canonical function is as a responder to Wnt signaling with an anti-apoptotic role ${ }^{58}$. In the nucleolus PPAN promotes rRNA maturation after it has been incorporated in the pre-60S. PPAN is presumably retained in the nucleolus via its binding to UBF or NPM1, and in response to stress it exits and is cleaved by caspases. While this pathway does not require p53, altered ribosome biogenesis by PPAN does correlate with accumulation of $\mathrm{p} 53^{31}$.

Another is the chaperone and guanine nucleotide exchange factor SmgGDS1 (or RAP1GDS1), which when cytoplasmic binds GTPases and promotes plasma membrane trafficking, alternatively in the nucleolus it is sequestered by UBF binding. The role of nucleolar SmgGDS1 is unclear although its depletion leads to reduced expression of $\sim 600$ genes, most of which are associated with G1 cell cycle arrest or nucleolar disruption, and are transcribed by the dimerization partner, Rb-like, E2F and multi-vuval class B (DREAM) transcription complex ${ }^{59}$. SmgGDS1 is overexpressed in cancers, thus may suppress unwanted NSP activation and promote malignancy ${ }^{59}$. In summary, the list of nucleolar proteins that are regulated by or are components of the p53-dependent and -independent NSP is ever growing. The challenge will be to identify under what conditions they are biologically important, and if they represent new mechanisms or targets that might be useful to treat diseases associated with nucleolar dysfunction.

\subsection{The nucleolus and genomic stability}

It has been suggested that the nucleolus can impact on genomic stability in a number of ways; as the rDNA is highly repetitive it is prone to HR, this would negatively 
impact on genome stability. The $\mathrm{PH}$ around the nucleolus is tightly packed, and as such, may provide a barrier to prevent HR occurring between the rDNA repeats. Not surprisingly then, disruption of the $\mathrm{PH}$ has been associated with genomic instability, premature aging and age-related neurodegenerative diseases ${ }^{7,60}$. The $\mathrm{PH}$ also assists in the preservation of nucleolar architecture; the silencing of the rDNA via epigenetic mediated repressive marks and the organization of nucleosome structures. As an extension to this, since rDNA is located on five separate chromosomes, it is also possible that the $\mathrm{PH}$ mediates interactions, both short and long range, between specific genes thus may regulate their accessibility and transcription. This is based on recent publications utilising circular chromosomal conformation capture (3 or 4C) techniques ${ }^{7,60}$. While we have accepted that the nucleolus is a hub for sensing stress, we are only just beginning to understand how it might also be a hub for genome maintenance, and Pol II /III gene regulation.

\section{The nucleolus and disease}

For over a century, pathologists have used changes in nucleolar morphology and number as a marker of disease. Abnormal nucleoli and increased rDNA transcription are accepted as common pathological features of many cancers ${ }^{8}$, and targeting rDNA transcription can be therapeutically used to treat cancer ${ }^{6,32,61}$. In addition, mutations in ribosomal components mediating reduced ribosome biogenesis and/or abnormal nucleoli have been attributed to the genetic diseases known collectively as ribosomopathies. While the involvement of classical ribosome biogenesis components have been assessed with respect to their impact on these disease, new roles for the nucleolus and the nucleolar proteomic studies may provide novel druggable targets and therapies.

\subsection{Ribosomopathies}

Ribosomopathies are diseases characterized broadly by the presence of mutations or deletions of genes related to ribosome biogenesis; i) genes encoding rproteins for Diamond Blackfan Anaemia (DBA) and 5q minus (5q-) syndrome; ii) genes associated with the synthesis or modification of the rRNA, for Treachers-Collins Syndrome (TCS), Dyskeratosis congenita (DC) and Cartilage hair hypoplasia (CHH); 
iii) genes encoding proteins (not rproteins) associated with the ribosome, for Shwachman-Diamond syndrome (SDS). Each of these diseases have similar and varying phenotypes which are summarized in Table $\mathbf{1}^{62-64}$.

While intriguing in nature, one interesting observation is that many of the ribosomopathy phenotypes tend to affect specific tissues rather than all. This could be due to either quantitative (translation capacity) and/or qualitative (targeted translation by specialized ribosomes) differences or dependent on the tissue $e^{62-64}$.

For example loss of one rprotein gene (haploinsufficency) allele may reduce its expression below a critical level for maintaining ribosome biogenesis in one cell type but not in another, thus leading to heterogeneous phenotypes and pathologies. That being said, this group of rare diseases represent a huge unmet need in the clinic, as in almost all cases treatments are palliative rather than curative. Importantly until we understand the mechanism(s) of action underlying these diseases, this is unlikely to change.

DBA: DBA is associated with mutations in rproteins, however only 17 of the $\sim 80$ possible have been identified, and in $25 \%$ of cases the mutations were in RPS19. This might be explained by the loss of certain rproteins only mildly perturbing ribosome biogenesis, not enough to activate p53 or, the phenotype is too severe for survival. While the classical p53NSP has been linked to the phenotype of DBA, so have p53independent mechanism(s) $)^{63-65}$.

Intriguingly, mutations in two non-rproteins also mediate a DBA-like phenotype, the putative RPS26 chaperone TSR2 and the haematopoetic transcription factor GATA$1^{66,67}$. Mutations in TSR2, reduced RPS26 transport to the nucleolus, thus phenocopying loss-of-function RPS26 mutations identified in DBA patients ${ }^{68}$. Mutations in GATA-1 reduced synthesis of the long form of GATA-1, a critical transcription factor in erythroid differentiation, thus altering the translational landscape and mediating a DBA phenotype. Interestingly, when the transcription profile of rprotein- verse GATA1-mediated DBA were compared there were overlaps and critical differences at the mRNA level ${ }^{69}$. OBrien ${ }^{69}$ proposed a model by which GATA-1 mutations reduced the expression of proteins required for ribosome synthesis, placing it upstream of rproteins, yet the end result for both is reduced 
translation. There are also examples where rprotein mutations reduce the translation of GATA-1 in $\mathrm{DBA}^{68}$. Together, these examples support the hypothesis that dysregulation of ribosome biogenesis and translation drives DBA pathology.

5q-syndrome: 5q-syndrome (a bone marrow disorder also called myelodysplastic syndrome) is caused by a deletion in the long arm of chromosome $5^{65}$ an area that includes 40 genes. This inclused three rproteins (RPS14, RPL7, RPLP1), two microRNAs (miR-145, miR146a) $)^{65,70}$ and other genes which mediate varying degrees of disease presentation (CSNK1A1 $1^{71}$, SPARC, CTNNA1 $1^{7,2} E G R 1^{73}$ ). Thus far, research has focussed on the RPS14 deletion in human CD34+ cells which was sufficient to recapitulate the $5 \mathrm{q}$-erythroid defect and reversed by deleting $\mathrm{p} 53^{74}$. Interestingly, a recent study suggestes this process is more complicated, describing an early p53independent erythroid defect followed by a p53-dependent $\operatorname{defect}^{75}$. To further complicate things, loss of the most recent 5q-associated gene, LARP1, which is known to stabilize 5'TOP mRNAs, reduced ribosome biogenesis and stabilized $\mathrm{p} 53^{76,77}$.

SDS: SDS is an autosomal recessive disease with $90 \%$ of cases arising from mutations in the Shwachman-Bodian Diamond syndrome (SBDS) gene ${ }^{78}$. While SBDS has been implicated in a cellular stress response $\mathrm{e}^{78,79}$ there is still confusion over the role of $\mathrm{p} 53$ in $\operatorname{SDS}^{78,80,81}$. Current studies demonstrate that SBDS is a cofactor for the elongation factor-like GTPase 1 (EFL1), which facilitates removal of eukaryotic initiation factor 6 (eIF6) from the $60 \mathrm{~S}$ during the final stage of maturation ${ }^{82}$. Not surprisingly, recently EFL1 mutations mediated clinical symptoms similar to those observed for $\operatorname{SDS}^{83}$. Mutations in DNAJC21, which is also required for the maturation of $60 \mathrm{~S}$ and can bind rRNA, have also been identified in SDS patients ${ }^{84,85}$.

TCS: Intriguingly, mutations in genes associated with rRNA synthesis cause TCS rather than DBA or 5q-syndrome. TCS is an autosomal dominant disorder mediated by TCOF1 or POLRID mutations, or recessive if the mutation is in POLR $1 C^{86-88}$. TCOF1 encodes the nucleolar phosphoprotein Treacle, which regulates rDNA transcription and pre-RNA methylation ${ }^{88-90}$, whereas POLRID and POLRIC encode subunits of Pol I and III respectively. Currently, at least for TCOF1 mutations, 
haploinsufficiency reduces rRNA synthesis and ribosome biogenesis/capacity thus induces p53NSP and apoptosis, predominantly of neural crest cells during embryonic development ${ }^{88-90}$.

DC: DC at a glance might be considered more akin to diseases associated with dysregulated telomerase function rather than ribosomopathies. To date, DKC1 (20$25 \%$ of sporadic cases), TERT and TERC mutations occur in $~ 64 \%$ of cases, with numerous other gene mutations identified in the rest ${ }^{91-95}$. Collectively, these mutations mediate telomere shortening and DNA damage, resulting in p53 stabilization and cell death $^{94}$. However, some of these genes have other functions which links them to ribosomopathies. For example, $D K C 1$ encodes the protein dyskerin which associates with numerous H/ACA small RNAs to form RNP complexes, these pseudouridylate small nucleolar (sno) RNAs and rRNAs ${ }^{95}$, thus when DKC1 is mutated translation is impaired $^{96}$, although some of the specifics are still controversial. Alternatively mutations in TERT or TERC alter telomere function and stability. Telomerase reverse transcriptase, along with telomerase RNA component forms an RNP, known as telomerase. Telomerase, like the H/ACA snoRNPs, also contains dyskerin, however in this case dyskerin promotes complex stability rather than pseudouridylation. Thus, all three genes are linked so perhaps there are subtypes of DC, some of which are ribosomopathies and others not.

CHH: CHH remains the sole ribosomopathy not linked to p53. It is caused by mutations in $R M R P$, which encodes a long non-coding RNA (liRMPR) that is a component of the mitochondrial RNA processing complex (RNase MRP enzyme). Nucleolar RNAse MRP enzyme cleaves the pre-rRNA and process the 5.8S rRNA $^{97,98}$. When $R M R P$ is mutated, liRMPR becomes unstable and is unable to bind the RNAse MRP complex thus impairing processing. The liRMPR is also then cleaved into two siRNA's (RMRP-S1 and S2) that have the potential to silence genes. Any of these liRMPR functions could contribute to the clinical symptoms of $\mathrm{CHH}^{99}$. An earlier study suggested liRMPR interacts with TERT to form a RNA-dependent RNA polymerase that produced double stranded RNAs, which were processed to siRNAs in a DICER-dependent manner, again capable of silencing genes ${ }^{100}$. Clearly 
there is considerable work required to understand the pathology of $\mathrm{CHH}$ and the contribution of rRNA defects to the pathology of the disease.

Others: Other putative ribosomopathies have been identified, such as Bowen-Conradi syndrome and North American Indian childhood cirrhosis syndrome (NAIC), which are extremely rare, and as a result, there is limited information about the mechanism underlying these diseases. Interestingly, both are mediated, at least in part, by mutations in genes critical for $18 \mathrm{~S}$ rRNA processing. Bowen-Conradi syndrome is mediated by mutations in the gene essential for mitotic growth 1 (EMG1), a pseudouridine methyltransferase, and NAIC is caused by mutations in the CIRHIA (hUTP4/Cirhin) ${ }^{101}$ gene which both encode factors that are components of the ribosomal small subunit (SSU) processome ${ }^{102}$. Undoubtedly this is not a completed list of ribosomopathies and as sequencing capabilities improve additional ribosomopathies associate with novel ribosomal gene related mutations will be identify.

\subsection{Cancer}

There is a long history and a well-accepted correlation between hyperactivated ribosome biogenesis, abnormal nucleoli and cancer. However, the exact mechanism by which elevated ribosome biogenesis contributes to cancer is less clear. Highly proliferative cancer cells require elevated translational capacity, an increased number of ribosomes per cell, which is often driven through oncogenes or loss of tumor suppressor pathways and the enhancement of ribosome biogenesis. Interestingly, not all tumour cells are highly proliferative, nor does the efficacy of targeting a nucleolarfunction necessarily correlate with proliferation rate (personal observation). One reason why tumor cells may have developed robust mechanisms to drive ribosome biogenesis, and promote nucleolar formation is a means to suppress the NSP and thus repress p53-dependent and -independent mechanisms that block cellular proliferation. Consistent with this, targeting the NSP with small molecule inhibitors that selectively inhibit Pol I transcription and rRNA synthesis have shown promise in the treatment of cancer $^{6,32}$. However, targeting the NSP to treat tumors is perhaps not as novel as we thought, retrospective studies reported that the mechanism of action for numerous 
chemotherapeutic drugs, at least in part, target the nucleolus, inhibit ribosome biogenesis, and mediate cell death via activation of $\mathrm{p} 53$, i.e. they activate the NSP ${ }^{103}$. While such drugs typically disrupt the nucleolar structure ${ }^{103}$, their other mechanism of action often cause unfavourable toxicities to normal cells. In contrast selective small molecule inhibitors of Pol I transcription (eg., CX-5461) are a new class of drug mediating NSP activation of p53 in the absence of global DNA damage ${ }^{61,104}$. In particular CX-5461 has opened up a new avenue for cancer therapy and spurred an intensive effort to develop new drugs that cause nucleolar stress without generic DNA damage; including an acridine derivative known as CID-765471 $105, \mathrm{BMH}-21^{106}$ and Inauzhin ${ }^{107}$. All three drugs activate the NSP in the absence of global DNA damage; while CID-765471 and BMH-21 do so by selectively degrading the RPA194 subunit of Pol I and disrupting rDNA transcription, Inauzhin inhibits SIRT1 and inosine monophosphate dehydrogenase 2 (IMPDH2), reducing nucleostemin expression and decreasing rRNA processing ${ }^{107}$. At this stage only CX-5461 is in clinical trial including a phase I trial for hematologic cancers (ACTRN12613001061729-Australia) and a phase I/II for triple negative breast cancer (NCT02719977-Canada).

\subsection{Parkinson, Huntington's, Alzheimer's disease and Multiple Sclerosis}

Interestingly, as in the case for many cancers, changes in the nucleoli are common in a number of age-related neurological disorders including Parkinson's (PD), Huntington's (HD) and Alzheimer's disease (AD). There is increasing evidence for dysregulated rDNA transcription, nucleolar dysfunction and induction of the p53NSP contributing to these diseases, as well as the normal aging process ${ }^{108}$. The possible contribution of other non-canonical roles for the nucleolus in neurological diseases and aging is unknown, but clearly warrants investigation.

PD: Five genes have been associated with familial PD; $\alpha$-synuclein $(S N C A)$, parkin (PARK2), PTEN-induced putative kinase 1 (PINK1), DJ-1 (PARK7), and Leucine-rich repeat kinase 2 (LRRK2). Mutations in at least two of these (PARK7, PARK2) are associated with nucleolar defects and altered rDNA synthesis. PARK7 mutations cause protein misfolding and is associated with autosomal recessive early-onset $\mathrm{PD}^{109}$, while mutations in PARK2, which encodes an E3 ubiquitin ligase (Parkin), are frequently identified in early-onset familial $\mathrm{PD}^{110}$. A number of these disease- 
associated genes also encode proteins that can modulate ribosome function, specifically translation ${ }^{111}$. While ribosome biogenesis and function is dysregulated in $\mathrm{PD}$, the details are unclear, thus more research to understand their full impact is required to uncover possible therapeutic targets.

HD: HD is associated with mutations in only one gene, Huntingtin, which, when mutated, results in protein misfolding and aggregation. One consequence of cytoplasmic aggregation is the disruption of global protein trafficking, which may negatively impact on the nucleolus, especially its roles in sequestrating proteins. Interestingly, nuclear aggregates of huntingtin interact with NPM1, which may act as a chaperone and shield the aggregate ${ }^{112}$. More directly, with respect to altering nucleolar functions, HD was linked to disruption of CBP-acetylation of UBF and increased methylation by SETDB1, the end result being reduced rDNA transcription $^{113}$. What is less clear, is how causative these impacts on the nucleolus are on HD pathology, especially given the broad range of other consequences nuclear huntingtin aggregates are likely to have.

AD: $\mathrm{AD}$ is a progressive chronic disorder characterized by $\beta$-amyloid plaques, Tau (Tubulin associated unit) pathology, neuronal cell death, and inflammatory responses. Recent studies have linked AD to dysregulated ribosome biogenesis and nucleolar function. Specifically reduced mRNA, and in some cases also protein expression, of a range of nucleolar chaperones and/or regulators of rDNA transcription (e.g. NCL, NPM1, and UBF) were identified in AD patients ${ }^{114}$. Decreased rDNA transcription was also reported, which correlated with hypermethylation (silencing) of the rDNA promoter, and disease progression ${ }^{115}$. An established marker for $\mathrm{AD}$ is aggregation of Tau, which is not only cytoplasmic but also localizes to the NORs, nucleus and nucleolus DFC. Thus Tau may modulate the formation of the nucleolar $\mathrm{PH}$, regulate rDNA transcription and ribosome assembly, and has also been implicated in the $\mathrm{NSP}^{116}$. Moreover, reduced nucleolar expression of PARP1 and fibrillarin were reported in the hippocampal cells of AD patients ${ }^{117}$, however the link to pathology is yet to be confirmed. 
Multiple Sclerosis (MS): Benign MS is a sub-group of non-active MS patients who are protected from long-term disability despite ongoing disease progression. Recently, high throughput microarray analysis identified a signature characterising benign $\mathrm{MS}^{118}$, which included reduced expression of the Pol I transcription pathway, down regulation of NFkB and upregulated p53-dependent apoptosis. Intriguingly, a second generation derivative of CX-5461 (RAM-589.555) was tested in models of experimental autoimmune encephalomyelitis and mediated selective induction of apoptosis in inflammatory cells. It is hoped that this drug may transform the active MS disease to the preferable benign subtype ${ }^{119}$.

\section{CONCLUSION}

Recent studies have revealed that the central role played by the nucleolus in cellular homeostasis beyond its canonical functions in synthesising ribosomes. It is clear that the nucleolus is no longer a bystander in the regulation of crucial cellular processes but a fully contributing player. These newly discovered functions range from detecting cellular stress through to maintaining genomic stability and even aging. The molecular mechanisms underlying these novel functions are beginning to be teased apart. In particular the discovery of multiple pathways and genes modulating the p53dependent and -independent NSP are providing new targets and approaches to treat cancers, ribosomopathies and neurodegenerative diseases associated with ribosome dysfunction. Indeed although the nucleolus was the first identified sub-nuclear body, it is only now some 180 years later that are we beginning to unlock the secrets to its plurifunctionality.

\section{References}

1. Konikkat S, Woolford JL. Principles of $60 \mathrm{~S}$ ribosomal subunit assembly emerging from recent studies in yeast. Biochemical Journal 2017;474(2):195214.

2. Diesch J, Hannan RD, Sanij E. Perturbations at the ribosomal genes loci are at the centre of cellular dysfunction and human disease. Cell \& bioscience 2014;4(1):43.

3. Derenzini M, Montanaro L, Trerè D. Ribosome biogenesis and cancer. Acta Histochemica 2017. 
4. Farley KI, Surovtseva Y, Merkel J, Baserga SJ. Determinants of mammalian nucleolar architecture. Chromosoma 2015;124(3):323-331.

5. Mangan H, Ó Gailín M, McStay B. Integrating the genomic architecture of human nucleolar organizer regions with the biophysical properties of nucleoli. The FEBS Journal 2017.

6. Bywater MJ, Pearson RB, McArthur GA, Hannan RD. Dysregulation of the basal RNA polymerase transcription apparatus in cancer. Nature reviews. Cancer 2013;13(5):299.

7. Tsekrekou M, Stratigi K, Chatzinikolaou G. The Nucleolus: In Genome Maintenance and Repair. International journal of molecular sciences 2017;18(7):1411.

8. Derenzini M, Montanaro L, Treré D. What the nucleolus says to a tumour pathologist. Histopathology 2009;54(6):753-762.

9. Campbell KJ, White RJ. MYC regulation of cell growth through control of transcription by RNA polymerases I and III. Cold Spring Harbor perspectives in medicine 2014;4(5):a018408.

10. Poortinga G, Quinn L, Hannan R. Targeting RNA polymerase I to treat MYCdriven cancer. Oncogene 2015;34(4):403-412.

11. Miller G, Panov KI, Friedrich JK, Trinkle- Mulcahy L, Lamond AI, Zomerdijk JC. hRRN3 is essential in the SL1- mediated recruitment of RNA polymerase I to rRNA gene promoters. The EMBO journal 2001;20(6):13731382.

12. Ray S, Panova T, Miller G, Volkov A, Porter AC, Russell J, Panov KI, Zomerdijk JC. Topoisomerase II $\alpha$ promotes activation of RNA polymerase I transcription by facilitating pre-initiation complex formation. Nature communications 2013;4:1598.

13. Hein N, Hannan KM, George AJ, Sanij E, Hannan RD. The nucleolus: an emerging target for cancer therapy. Trends in molecular medicine 2013;19(11):643-654.

14. Hung SS, Lesmana A, Peck A, Lee R, Tchoubrieva E, Hannan KM, Lin J, Sheppard KE, Jastrzebski K, Quinn LM. Cell cycle and growth stimuli regulate different steps of RNA polymerase I transcription. Gene 2017;612:3648.

15. Albert B, Perez-Fernandez J, Léger-Silvestre I, Gadal O. Regulation of ribosomal RNA production by RNA polymerase I: does elongation come first? Genetics research international 2012;2012.

16. Zhang Y, French SL, Beyer AL, Schneider DA. The transcription factor THO promotes transcription initiation and elongation by RNA polymerase I. Journal of Biological Chemistry 2016;291(6):3010-3018.

17. Tomecki R, Sikorski PJ, Zakrzewska- Placzek M. Comparison of preribosomal RNA processing pathways in yeast, plant and human cells-focus on coordinated action of endo- and exoribonucleases. FEBS letters 2017.

18. Henras AK, Plisson- Chastang C, O'Donohue MF, Chakraborty A, Gleizes PE. An overview of pre- ribosomal RNA processing in eukaryotes. Wiley Interdisciplinary Reviews: RNA 2015;6(2):225-242.

19. Hiraishi N, Ishida Y-i, Sudo H, Nagahama M. WDR74 participates in an early cleavage of the pre-rRNA processing pathway in cooperation with the 
nucleolar AAA-ATPase NVL2. Biochemical and Biophysical Research Communications 2017.

20. de la Cruz J, Karbstein K, Woolford Jr JL. Functions of ribosomal proteins in assembly of eukaryotic ribosomes in vivo. Annual review of biochemistry 2015;84:93-129.

21. Kressler D, Hurt E, Bergler H, Baßler J. The power of AAA-ATPases on the road of pre-60S ribosome maturation-molecular machines that strip preribosomal particles. Biochimica et Biophysica Acta (BBA)-Molecular Cell Research 2012;1823(1):92-100.

22. Gamalinda M, Woolford Jr JL. Paradigms of ribosome synthesis: lessons learned from ribosomal proteins. Translation 2015;3(1):e975018.

23. Ghalei H, Trepreau J, Collins JC, Bhaskaran H, Strunk BS, Karbstein K. The ATPase Fap7 Tests the Ability to Carry Out Translocation-like Conformational Changes and Releases Dim1 during 40S Ribosome Maturation. Molecular cell 2017;67(6):990-1000. e3.

24. Andersen JS, Lyon CE, Fox AH, Leung AK, Lam YW, Steen H, Mann M, Lamond AI. Directed proteomic analysis of the human nucleolus. Current biology 2002;12(1):1-11.

25. Scherl A, Couté Y, Déon C, Callé A, Kindbeiter K, Sanchez J-C, Greco A, Hochstrasser D, Diaz J-J. Functional proteomic analysis of human nucleolus. Molecular biology of the cell 2002;13(11):4100-4109.

26. Ahmad Y, Boisvert F-M, Gregor P, Cobley A, Lamond AI. NOPdb: nucleolar proteome database-2008 update. Nucleic acids research 2008;37(suppl_1):D181-D184.

27. Andersen JS, Lam YW, Leung AK, Ong S-E. Nucleolar proteome dynamics. Nature 2005;433(7021):77.

28. Antoniali G, Lirussi L, Poletto M, Tell G. Emerging roles of the nucleolus in regulating the DNA damage response: the noncanonical DNA repair enzyme APE1/Ref-1 as a paradigmatical example. Antioxidants \& redox signaling 2014;20(4):621-639.

29. Shi J, Huang C, Huang S, Yao C. snoRNAs associate with mRNA 3' processing complex: New wine in old bottles. RNA biology 2017:1-4.

30. Berndt H, Harnisch C, Rammelt C, Stöhr N, Zirkel A, Dohm JC, Himmelbauer $\mathrm{H}$, Tavanez J-P, Hüttelmaier $\mathrm{S}$, Wahle E. Maturation of mammalian H/ACA box snoRNAs: PAPD5-dependent adenylation and PARN-dependent trimming. Rna 2012;18(5):958-972.

31. Russo A, Russo G. Ribosomal proteins control or bypass p53 during nucleolar stress. International journal of molecular sciences 2017;18(1):140.

32. Woods SJ, Hannan KM, Pearson RB, Hannan RD. The nucleolus as a fundamental regulator of the p53 response and a new target for cancer therapy. Biochimica et Biophysica Acta (BBA)-Gene Regulatory Mechanisms 2015;1849(7):821-829.

33. Leung AK, Lamond AI. The dynamics of the nucleolus. Critical Reviews ${ }^{\mathrm{TM}}$ in Eukaryotic Gene Expression 2003;13(1).

34. Thoms HC, Loveridge CJ, Simpson J, Clipson A, Reinhardt K, Dunlop MG, Stark LA. Nucleolar targeting of RelA (p65) is regulated by COMMD1dependent ubiquitination. Cancer research 2010;70(1):139-149. 
35. Bernardi R, Scaglioni PP, Bergmann S, Horn HF, Vousden KH, Pandolfi PP. PML regulates p53 stability by sequestering Mdm2 to the nucleolus. Nature cell biology 2004;6(7).

36. Bański P, Mahboubi H, Kodiha M, Shrivastava S, Kanagaratham C, Stochaj $\mathrm{U}$. Nucleolar targeting of the chaperone hsc70 is regulated by stress, cell signaling, and a composite targeting signal which is controlled by autoinhibition. Journal of Biological Chemistry 2010;285(28):21858-21867.

37. Federici L, Falini B. Nucleophosmin mutations in acute myeloid leukemia: a tale of protein unfolding and mislocalization. Protein science 2013;22(5):545556.

38. Martin RM, Ter-Avetisyan G, Herce HD, Ludwig AK, Lättig-Tünnemann G, Cardoso MC. Principles of protein targeting to the nucleolus. Nucleus 2015;6(4):314-325.

39. Kressler D, Hurt E, Baßler J. A puzzle of life: crafting ribosomal subunits. Trends in biochemical sciences 2017;42(8):640-654.

40. de los Santos-Velázquez AI, de Oya IG, Manzano-López J, Monje-Casas F. Late rDNA condensation ensures timely Cdc14 release and coordination of mitotic exit signaling with nucleolar segregation. Current Biology 2017;27(21):3248-3263. e5.

41. Lirussi L, Antoniali G, Vascotto C, D'Ambrosio C, Poletto M, Romanello M, Marasco D, Leone M, Quadrifoglio F, Bhakat KK. Nucleolar accumulation of APE1 depends on charged lysine residues that undergo acetylation upon genotoxic stress and modulate its BER activity in cells. Molecular biology of the cell 2012;23(20):4079-4096.

42. van Sluis M, McStay B. A localized nucleolar DNA damage response facilitates recruitment of the homology-directed repair machinery independent of cell cycle stage. Genes \& development 2015;29(11):1151-1163.

43. Harding SM, Boiarsky JA, Greenberg RA. ATM dependent silencing links nucleolar chromatin reorganization to DNA damage recognition. Cell reports 2015;13(2):251-259.

44. Rubbi CP, Milner J. Disruption of the nucleolus mediates stabilization of p53 in response to DNA damage and other stresses. The EMBO journal 2003;22(22):6068-6077.

45. Mills EW, Green R. Ribosomopathies: There's strength in numbers. Science 2017;358(6363):eaan2755.

46. Boulon S, Westman BJ, Hutten S, Boisvert F-M, Lamond AI. The nucleolus under stress. Molecular cell 2010;40(2):216-227.

47. Sloan KE, Bohnsack MT, Watkins NJ. The 5S RNP couples p53 homeostasis to ribosome biogenesis and nucleolar stress. Cell reports 2013;5(1):237-247.

48. Donati G, Peddigari S, Mercer CA, Thomas G. 5S ribosomal RNA is an essential component of a nascent ribosomal precursor complex that regulates the Hdm2-p53 checkpoint. Cell reports 2013;4(1):87-98.

49. Macias E, Jin A, Deisenroth C, Bhat K, Mao H, Lindström MS, Zhang Y. An ARF-independent c-MYC-activated tumor suppression pathway mediated by ribosomal protein-Mdm2 Interaction. Cancer cell 2010;18(3):231-243.

50. Nicolas E, Parisot P, Pinto-Monteiro C, De Walque R, De Vleeschouwer C, Lafontaine DL. Involvement of human ribosomal proteins in nucleolar structure and p53-dependent nucleolar stress. Nature communications 2016;7. 
51. Takagi M, Absalon MJ, McLure KG, Kastan MB. Regulation of p53 translation and induction after DNA damage by ribosomal protein L26 and nucleolin. Cell 2005;123(1):49-63.

52. Cui D, Li L, Lou H, Sun H, Ngai S, Shao G, Tang J. The ribosomal protein S26 regulates p53 activity in response to DNA damage. Oncogene 2014;33(17):2225-2235.

53. Xie N, Ma L, Zhu F, Zhao W, Tian F, Yuan F, Fu J, Huang D, Lv C, Tong T. Regulation of the Mdm2-p53 pathway by the nucleolar protein CSIG in response to nucleolar stress. Scientific reports 2016;6.

54. Lo D, Lu H. Nucleostemin: another nucleolar" Twister" of the p53-MDM2 loop. Cell Cycle 2010;9(16):3247-3252.

55. Dong Z, Zhu C, Zhan Q, Jiang W. The roles of RRP15 in nucleolar formation, ribosome biogenesis and checkpoint control in human cells. Oncotarget 2017;8(8):13240.

56. Donati G, Brighenti E, Vici M, Mazzini G, Treré D, Montanaro L, Derenzini M. Selective inhibition of rRNA transcription downregulates E2F-1: a new p53-independent mechanism linking cell growth to cell proliferation. J Cell Sci 2011;124(17):3017-3028.

57. Pagliara V, Saide A, Mitidieri E, di Villa BRdE, Sorrentino R, Russo G, Russo A. 5-FU targets rpL3 to induce mitochondrial apoptosis via cystathionine- $\beta$ synthase in colon cancer cells lacking p53. Oncotarget 2016;7(31):50333.

58. Pfister AS, Keil M, Kühl M. The Wnt target protein Peter Pan defines a novel p53-independent nucleolar stress-response pathway. Journal of Biological Chemistry 2015;290(17):10905-10918.

59. Gonyo P, Bergom C, Brandt A, Tsaih S, Sun Y, Bigley T, Lorimer E, Terhune $\mathrm{S}$, Rui H, Flister M. SmgGDS is a transient nucleolar protein that protects cells from nucleolar stress and promotes the cell cycle by regulating DREAM complex gene expression. Oncogene 2017.

60. Srivastava R, Srivastava R, Ahn SH. The epigenetic pathways to ribosomal DNA silencing. Microbiology and Molecular Biology Reviews 2016;80(3):545-563.

61. Rebello RJ, Kusnadi E, Cameron DP, Pearson HB, Lesmana A, Devlin JR, Drygin D, Clark AK, Porter L, Pedersen J and others. The Dual Inhibition of RNA Pol I Transcription and PIM Kinase as a New Therapeutic Approach to Treat Advanced Prostate Cancer. Clin Cancer Res 2016;22(22):5539-5552.

62. De Keersmaecker K, Sulima SO, Dinman JD. Ribosomopathies and the paradox of cellular hypo-to hyperproliferation. Blood 2015;125(9):1377-1382.

63. Danilova N, Gazda HT. Ribosomopathies: how a common root can cause a tree of pathologies. Disease models \& mechanisms 2015;8(9):1013-1026.

64. Yelick PC, Trainor PA. Ribosomopathies: global process, tissue specific defects. Rare Diseases 2015;3(1):e1025185.

65. Narla A, Ebert BL. Ribosomopathies: human disorders of ribosome dysfunction. Blood 2010;115(16):3196-3205.

66. Gripp KW, Curry C, Olney AH, Sandoval C, Fisher J, Chong JXL, Pilchman L, Sahraoui R, Stabley DL, Sol- Church K. Diamond-Blackfan anemia with mandibulofacial dystostosis is heterogeneous, including the novel DBA genes TSR2 and RPS28. American Journal of Medical Genetics Part A 2014;164(9):2240-2249. 
67. Ludwig LS, Gazda HT, Eng JC, Eichhorn SW, Thiru P, Ghazvinian R, George TI, Gotlib JR, Beggs AH, Sieff CA. Altered translation of GATA1 in Diamond-Blackfan anemia. Nature medicine 2014;20(7):748-753.

68. Sakamoto KM. Lost in translation: RP and GATA1 mutations in DBA. Blood 2017;129(23):3048-3049.

69. O'Brien KA, Farrar JE, Vlachos A, Anderson SM, Tsujiura CA, Lichtenberg J, Blanc L, Atsidaftos E, Elkahloun A, An X. Molecular convergence in ex vivo models of Diamond-Blackfan anemia. Blood 2017;129(23):3111-3120.

70. Starczynowski DT, Kuchenbauer F, Argiropoulos B, Sung S, Morin R, Muranyi A, Hirst M, Hogge D, Marra M, Wells RA. Identification of miR-145 and miR-146a as mediators of the 5q-syndrome phenotype. Nature medicine 2010;16(1):49-58.

71. Bello E, Pellagatti A, Shaw J, Mecucci C, Kušec R, Killick S, Giagounidis A, Raynaud S, Calasanz MJ, Fenaux P. CSNK1A1 mutations and gene expression analysis in myelodysplastic syndromes with del (5q). British journal of haematology 2015;171(2):210-214.

72. Liu TX, Becker MW, Jelinek J, Wen-Shu W, Deng M, Mikhalkevich N, Hsu $\mathrm{K}$, Bloomfield CD, Stone RM, DeAngelo DJ. Chromosome 5q deletion and epigenetic suppression of the gene encoding [alpha]-catenin (CTNNA1) in myeloid cell transformation. Nature medicine 2007;13(1):78.

73. Joslin JM, Fernald AA, Tennant TR, Davis EM, Kogan SC, Anastasi J, Crispino JD, Le Beau MM. Haploinsufficiency of EGR1, a candidate gene in the del (5q), leads to the development of myeloid disorders. Blood 2007;110(2):719-726.

74. Barlow JL, Drynan LF, Hewett DR, Holmes LR, Lorenzo-Abalde S, Lane AL, Jolin HE, Pannell R, Middleton AJ, Wong SH. A p53-dependent mechanism underlies macrocytic anemia in a mouse model of human 5q-syndrome. Nature medicine 2010;16(1):59-66.

75. Ear J, Hsueh J, Nguyen M, Zhang Q, Sung V, Chopra R, Sakamoto KM, Lin S. A Zebrafish Model of 5q-Syndrome Using CRISPR/Cas9 Targeting RPS14 Reveals a p53-Independent and p53-Dependent Mechanism of Erythroid Failure. Journal of Genetics and Genomics 2016;43(5):307-318.

76. Gentilella A, Morón-Duran FD, Fuentes P, Zweig-Rocha G, Riaño-Canalias F, Pelletier J, Ruiz M, Turón G, Castaño J, Tauler A. Autogenous Control of 5' TOP mRNA Stability by 40S Ribosomes. Molecular Cell 2017;67(1):55-70. e4.

77. Dutt S, Narla A, Lin K, Mullally A, Abayasekara N, Megerdichian C, Wilson FH, Currie T, Khanna-Gupta A, Berliner N. Haploinsufficiency for ribosomal protein genes causes selective activation of p53 in human erythroid progenitor cells. Blood 2011;117(9):2567-2576.

78. Warren AJ. Molecular basis of the human ribosomopathy ShwachmanDiamond syndrome. Advances in Biological Regulation 2017.

79. Ball HL, Zhang B, Riches JJ, Gandhi R, Li J, Rommens JM, Myers JS. Shwachman-Bodian Diamond syndrome is a multi-functional protein implicated in cellular stress responses. Human molecular genetics 2009;18(19):3684-3695.

80. Provost E, Wehner KA, Zhong X, Ashar F, Nguyen E, Green R, Parsons MJ, Leach SD. Ribosomal biogenesis genes play an essential and p53-independent 
role in zebrafish pancreas development. Development 2012;139(17):32323241 .

81. Zambetti NA, Bindels EM, Van Strien PM, Valkhof MG, Adisty MN, Hoogenboezem RM, Sanders MA, Rommens JM, Touw IP, Raaijmakers MH. Deficiency of the ribosome biogenesis gene Sbds in hematopoietic stem and progenitor cells causes neutropenia in mice by attenuating lineage progression in myelocytes. haematologica 2015;100(10):1285-1293.

82. Weis F, Giudice E, Churcher M, Jin L, Hilcenko C, Wong CC, Traynor D, Kay RR, Warren AJ. Mechanism of eIF6 release from the nascent $60 \mathrm{~S}$ ribosomal subunit. Nature structural \& molecular biology 2015;22(11):914919.

83. Stepensky P, Chacón-Flores M, Kim KH, Abuzaitoun O, Bautista-Santos A, Simanovsky N, Siliqi D, Altamura D, Méndez-Godoy A, Gijsbers A. Mutations in EFL1, an SBDS partner, are associated with infantile pancytopenia, exocrine pancreatic insufficiency and skeletal anomalies in a Shwachman-Diamond like syndrome. Journal of Medical Genetics 2017:jmedgenet-2016-104366.

84. Dhanraj S, Matveev A, Li H, Lauhasurayotin S, Jardine L, Cada M, Zlateska B, Tailor CS, Zhou J, Mendoza-Londono R. Biallelic mutations in DNAJC21 cause Shwachman-Diamond syndrome. Blood 2017;129(11):1557-1562.

85. Tummala H, Walne AJ, Williams M, Bockett N, Collopy L, Cardoso S, Ellison A, Wynn R, Leblanc T, Fitzgibbon J. DNAJC21 mutations link a cancer-prone bone marrow failure syndrome to corruption in 60S ribosome subunit maturation. The American Journal of Human Genetics 2016;99(1):115-124.

86. Renju R, Varma BR, Kumar SJ, Kumaran P. Mandibulofacial dysostosis (Treacher Collins syndrome): A case report and review of literature. Contemporary clinical dentistry 2014;5(4):532.

87. Dauwerse JG, Dixon J, Seland S, Ruivenkamp CA, van Haeringen A, Hoefsloot LH, Peters DJ, Clement-de Boers A, Daumer-Haas C, Maiwald R. Mutations in genes encoding subunits of RNA polymerases I and III cause Treacher Collins syndrome. Nature genetics 2011;43(1):20-22.

88. Sakai D, Trainor PA. Face off against ROS: Tcof1/Treacle safeguards neuroepithelial cells and progenitor neural crest cells from oxidative stress during craniofacial development. Development, growth \& differentiation 2016.

89. Dixon J, Jones NC, Sandell LL, Jayasinghe SM, Crane J, Rey J-P, Dixon MJ, Trainor PA. Tcof1/Treacle is required for neural crest cell formation and proliferation deficiencies that cause craniofacial abnormalities. Proceedings of the National Academy of Sciences 2006;103(36):13403-13408.

90. Jones NC, Lynn ML, Gaudenz K, Sakai D, Aoto K, Rey J-P, Glynn EF, Ellington L, Du C, Dixon J. Prevention of the neurocristopathy Treacher Collins syndrome through inhibition of p53 function. Nature medicine 2008;14(2):125.

91. Alter BP, Giri N, Savage SA, Rosenberg PS. Cancer in dyskeratosis congenita. Blood 2009;113(26):6549-6557. 
92. Nelson ND, Bertuch AA. Dyskeratosis congenita as a disorder of telomere maintenance. Mutation Research/Fundamental and Molecular Mechanisms of Mutagenesis 2012;730(1):43-51.

93. Karunakaran A, Ravindran R, Arshad M, Ram MK, Laxmi M. Dyskeratosis congenita: a report of two cases. Case reports in dentistry 2013;2013.

94. Fok WC, de Oliveira Niero EL, Dege C, Brenner KA, Sturgeon CM, Batista LFZ. p53 mediates failure of human definitive hematopoiesis in dyskeratosis congenita. Stem cell reports 2017;9(2):409-418.

95. Trahan C, Dragon F. Dyskeratosis congenita mutations in the H/ACA domain of human telomerase RNA affect its assembly into a pre-RNP. Rna 2009;15(2):235-243.

96. Ruggero D, Grisendi S, Piazza F, Rego E, Mari F, Rao PH, Cordon-Cardo C, Pandolfi PP. Dyskeratosis congenita and cancer in mice deficient in ribosomal RNA modification. Science 2003;299(5604):259-262.

97. Ridanpää M, van Eenennaam H, Pelin K, Chadwick R, Johnson C, Yuan B, Pruijn G, Salmela R, Rockas S, Mäkitie O. Mutations in the RNA component of RNase MRP cause a pleiotropic human disease, cartilage-hair hypoplasia. Cell 2001;104(2):195-203.

98. Shao Y, Ye M, Li Q, Sun W, Ye G, Zhang X, Yang Y, Xiao B, Guo J. LncRNA-RMRP promotes carcinogenesis by acting as a miR-206 sponge and is used as a novel biomarker for gastric cancer. Oncotarget 2016;7(25):37812.

99. Rogler LE, Kosmyna B, Moskowitz D, Bebawee R, Rahimzadeh J, Kutchko K, Laederach A, Notarangelo LD, Giliani S, Bouhassira E. Small RNAs derived from IncRNA RNase MRP have gene-silencing activity relevant to human cartilage-hair hypoplasia. Human molecular genetics 2013;23(2):368382.

100. Maida Y, Yasukawa M, Furuuchi M, Lassmann T, Possemato R, Okamoto N, Kasim V, Hayashizaki Y, Hahn WC, Masutomi K. An RNA-dependent RNA polymerase formed by TERT and the RMRP RNA. Nature 2009;461(7261):230-235.

101. Freed EF, Baserga SJ. The C-terminus of Utp4, mutated in childhood cirrhosis, is essential for ribosome biogenesis. Nucleic acids research 2010;38(14):4798-4806.

102. Armistead J, Hemming R, Patel N, Triggs-Raine B. Mutation of EMG1 causing Bowen-Conradi syndrome results in reduced cell proliferation rates concomitant with $\mathrm{G} 2 / \mathrm{M}$ arrest and $18 \mathrm{~S}$ rRNA processing delay. BBA clinical 2014;1:33-43.

103. Burger K, Mühl B, Harasim T, Rohrmoser M, Malamoussi A, Orban M, Kellner M, Gruber-Eber A, Kremmer E, Hölzel M. Chemotherapeutic drugs inhibit ribosome biogenesis at various levels. Journal of Biological Chemistry 2010;285(16):12416-12425.

104. Bywater MJ, Poortinga G, Sanij E, Hein N, Peck A, Cullinane C, Wall M, Cluse L, Drygin D, Anderes $\mathrm{K}$. Inhibition of RNA polymerase $\mathrm{I}$ as a therapeutic strategy to promote cancer-specific activation of p53. Cancer cell 2012;22(1):51-65.

105. Morgado-Palacin L, Llanos S, Urbano-Cuadrado M, Blanco-Aparicio C, Megias D, Pastor J, Serrano M. Non-genotoxic activation of p53 through the 
RPL11-dependent ribosomal stress pathway. Carcinogenesis 2014;35(12):2822-2830.

106. Peltonen K, Colis L, Liu H, Trivedi R, Moubarek MS, Moore HM, Bai B, Rudek MA, Bieberich CJ, Laiho M. A targeting modality for destruction of RNA polymerase I that possesses anticancer activity. Cancer cell 2014;25(1):77-90.

107. Zhang Q, Zhou X, Wu R, Mosley A, Zeng SX, Xing Z, Lu H. The role of IMP dehydrogenase 2 in Inauhzin-induced ribosomal stress. Elife 2014;3:e03077.

108. Szybińska A, Leśniak W. P53 Dysfunction in Neurodegenerative DiseasesThe Cause or Effect of Pathological Changes? Aging and Disease 2017;8(4):506.

109. Antipova D, Bandopadhyay R. Expression of DJ-1 in Neurodegenerative Disorders. DJ-1/PARK7 Protein: Springer; 2017. p 25-43.

110. Zhang C-W, Hang L, Yao T-P, Lim K-L. Parkin regulation and neurodegenerative disorders. Frontiers in aging neuroscience 2016;7:248.

111. Taymans J-M, Nkiliza A, Chartier-Harlin M-C. Deregulation of protein translation control, a potential game-changing hypothesis for Parkinson's disease pathogenesis. Trends in molecular medicine 2015;21(8):466-472.

112. Woerner AC, Frottin F, Hornburg D, Feng LR, Meissner F, Patra M, Tatzelt J, Mann M, Winklhofer KF, Hartl FU. Cytoplasmic protein aggregates interfere with nucleocytoplasmic transport of protein and RNA. Science 2016;351(6269):173-176.

113. Lee J, Hwang YJ, Ryu H, Kowall NW, Ryu H. Nucleolar dysfunction in Huntington's disease. Biochimica et Biophysica Acta (BBA)-Molecular Basis of Disease 2014;1842(6):785-790.

114. Garcia-Esparcia P, Hernández-Ortega K, Koneti A, Gil L, Delgado-Morales R, Castaño E, Carmona M, Ferrer I. Altered machinery of protein synthesis is region-and stage-dependent and is associated with $\alpha$-synuclein oligomers in Parkinson's disease. Acta neuropathologica communications 2015;3(1):76.

115. Pietrzak M, Rempala G, Nelson PT, Zheng J-J, Hetman M. Epigenetic silencing of nucleolar rRNA genes in Alzheimer's disease. PloS one 2011;6(7):e22585.

116. Bukar Maina M, Al-Hilaly YK, Serpell LC. Nuclear tau and its potential role in Alzheimer's disease. Biomolecules 2016;6(1):9.

117. Zeng J, Libien J, Shaik F, Wolk J, Hernández AI. Nucleolar PARP-1 expression is decreased in alzheimer's disease: consequences for epigenetic regulation of RDNA and cognition. Neural plasticity 2016;2016.

118. Achiron A, Feldman A, Magalashvili D, Dolev M, Gurevich M. Suppressed RNA-polymerase 1 pathway is associated with benign multiple sclerosis. PloS one 2012;7(10):e46871.

119. Achiron A, Zilkha-Falb R, Mashiach R, Gurevich M. RAM-589.555 a new Polymerase-1 inhibitor as innovative targeted-treatment for multiple sclerosis. Journal of neuroimmunology 2017;302:41-48. 


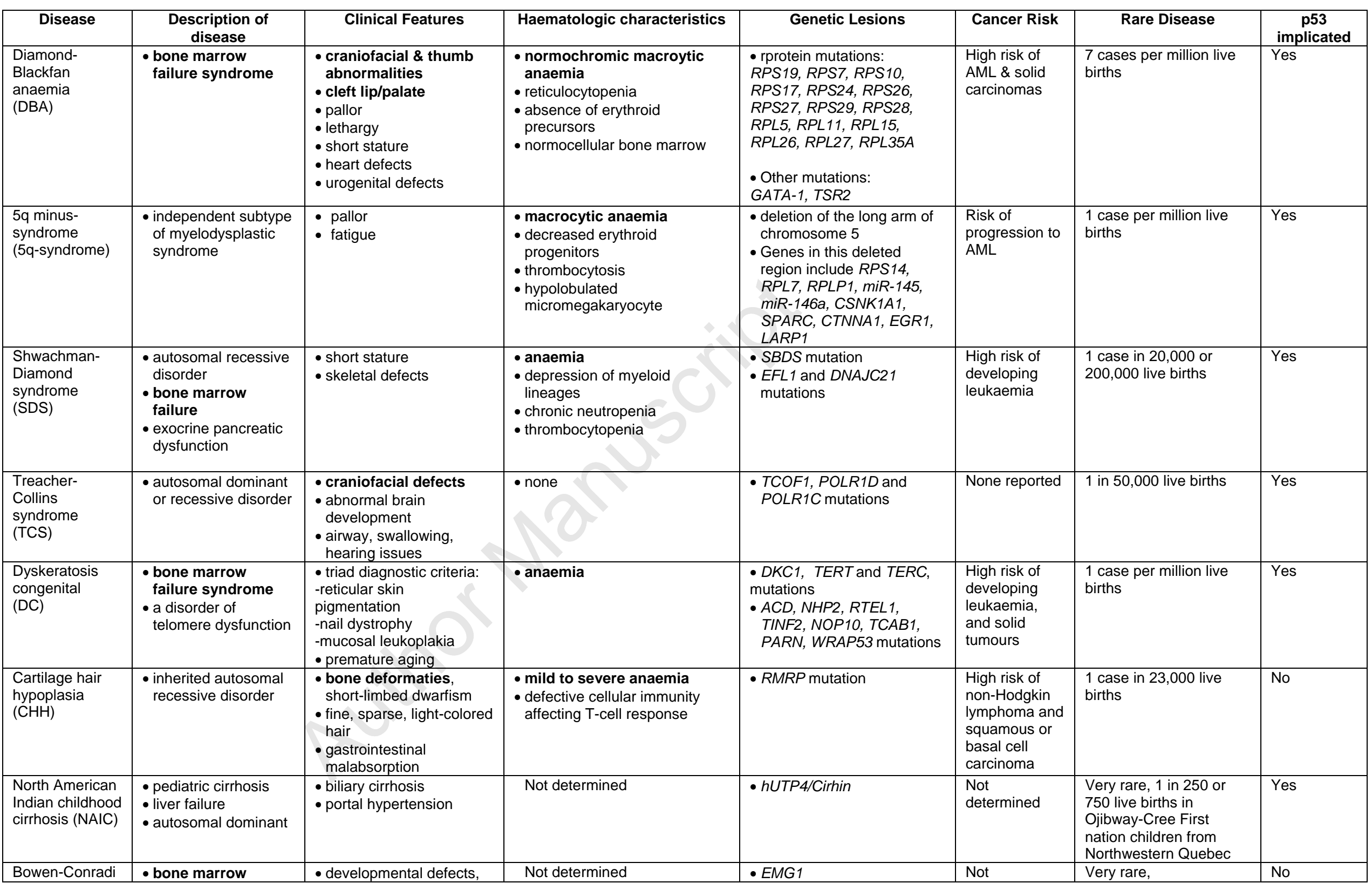

This article is protected by copyright. All rights reserved 


\begin{tabular}{|l|l|l|l|l|l|l|}
\hline syndrome & $\begin{array}{l}\text { failure syndrome } \\
\text { - autosomal dominant } \\
\text { - death in early } \\
\text { childhood }\end{array}$ & $\begin{array}{l}\text { growth retardation } \\
\text { psychomotor defects } \\
\text { m microcephaly, prominent } \\
\text { nose } \\
\text { central nervous system } \\
\text { defects }\end{array}$ & & & determined & $\begin{array}{l}1 / 355 \text { in Hutterite } \\
\text { population only }\end{array}$ \\
\hline
\end{tabular}

This article is protected by copyright. All rights reserved 


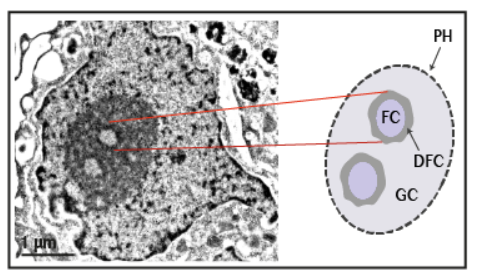

Figure

This article is protected by copyright. All rights reserved 


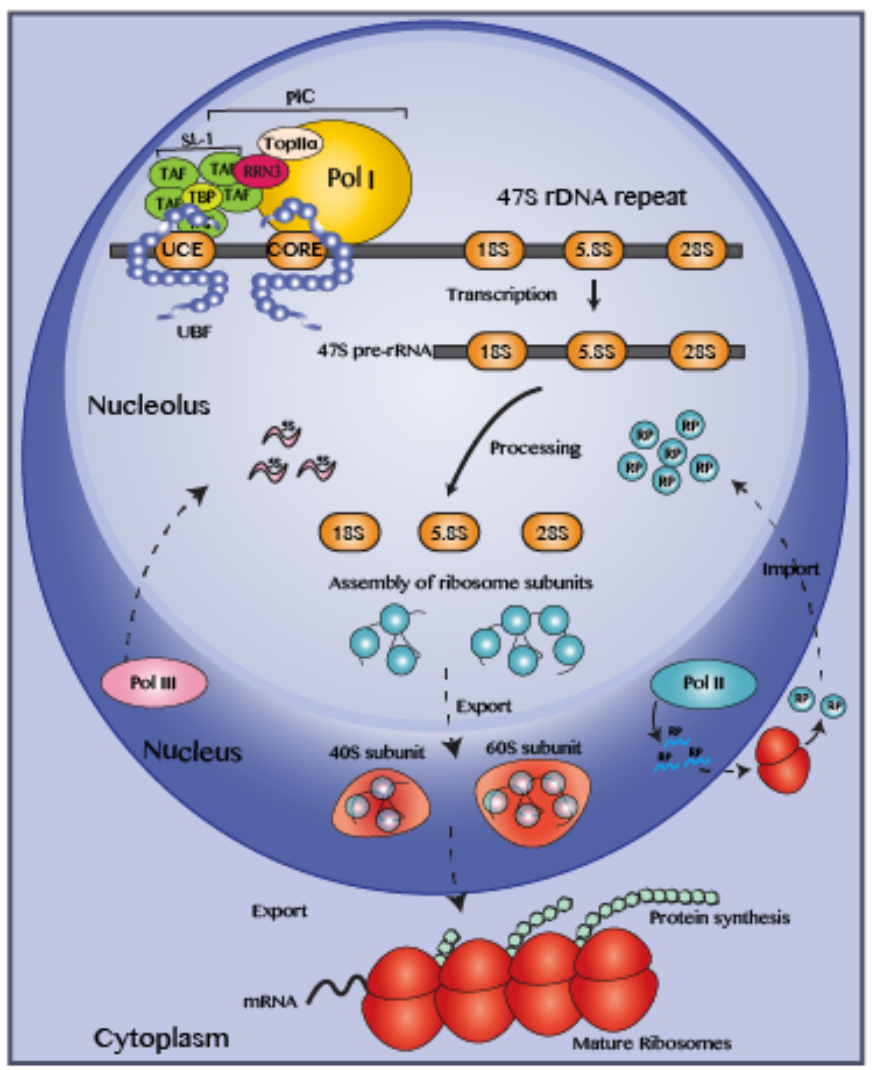

Figure 2

This article is protected by copyright. All rights reserved 


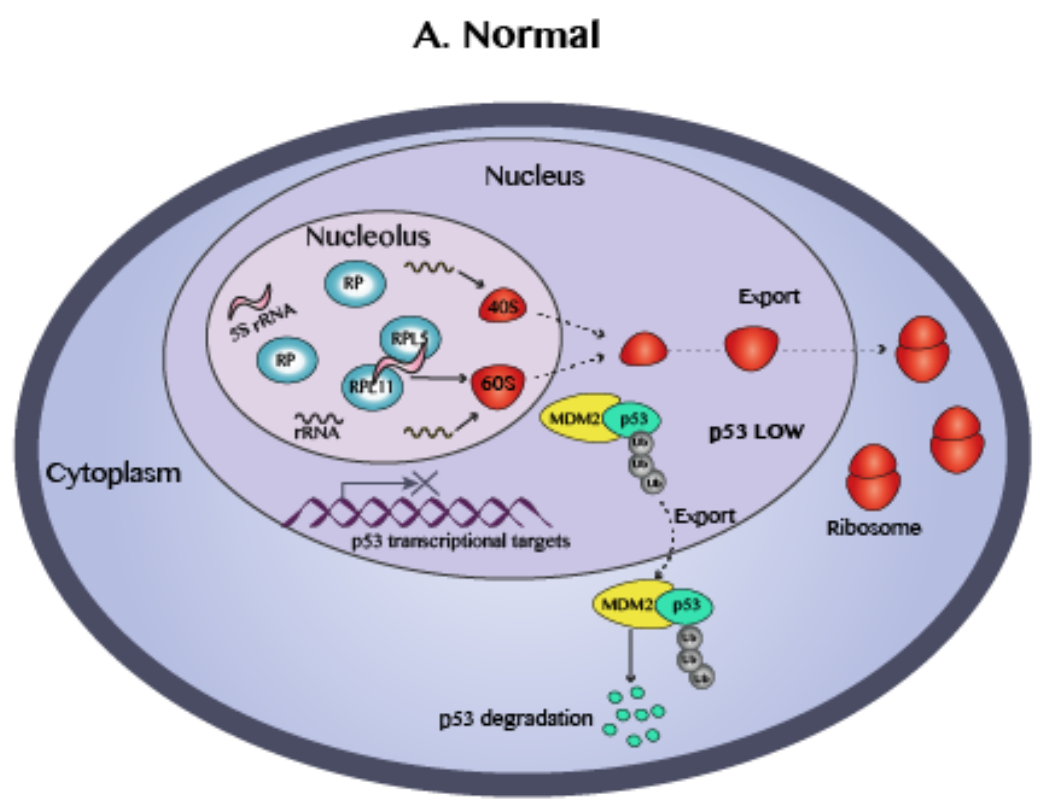

\section{B. p53 Nucleolar surveillance pathway (p53NSP)}

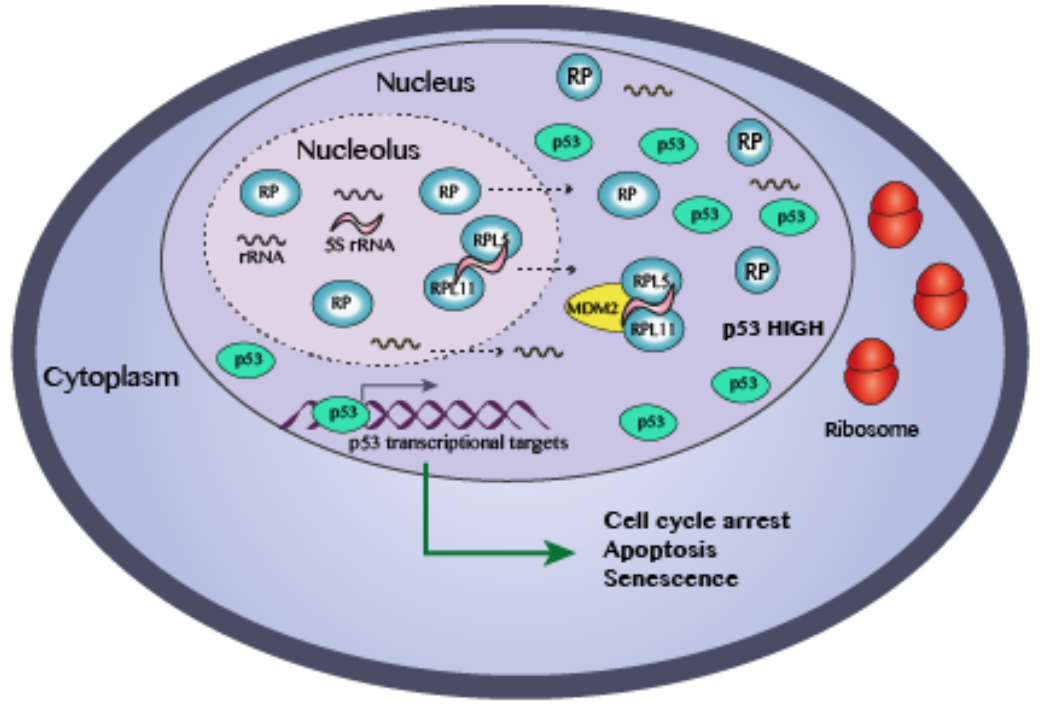

Figure 3

This article is protected by copyright. All rights reserved 


\section{University Library}

\section{- M M N E R VA A gateway to Melbourne's research publications}

Minerva Access is the Institutional Repository of The University of Melbourne

Author/s:

Villacis, LN;Wong, MS;Ferguson, LL;Hein, N;George, AJ;Hannan, KM

Title:

New Roles for the Nucleolus in Health and Disease

Date:

2018-05-01

Citation:

Villacis, L. N., Wong, M. S., Ferguson, L. L., Hein, N., George, A. J. \& Hannan, K. M.

(2018). New Roles for the Nucleolus in Health and Disease. BIOESSAYS, 40 (5), https:// doi.org/10.1002/bies.201700233.

Persistent Link:

http://hdl.handle.net/11343/283795 